\title{
Content adaptation procedures to cater for students with diverse academic backgrounds in delivering Textile, Clothing and Design programmes in Zimbabwe. A case study of two universities of technology
}

\author{
Felisia Chimbindi, S. Rembe \\ Senior Lecturer, \\ Chinhoyi University of Technology, Private Bag 7724, Chinhoyi, Zimbabwe. \\ Professor University of Fort Hare Lecturer, South Africa
}

\begin{abstract}
Universities of technology in Zimbabwe enrol students with various background educational qualifications for Textile, Clothing and Design programmes. The students are combined and learn in same class resulting in high students' failure rate, drop outs, late completion of degree programmes, and poor performance of graduates. Thus researchers sought to examine curriculum adaptation procedures used to cater for the students. Post-positivism paradigm in mixed method research approach was adopted for the study. Interviews with TCD management, document analysis, and questionnaire with lecturers yielded qualitative and quantitative data. Findings revealed that lecturers employed various uncoordinated methods to adapt the curriculum content to cater for the students
\end{abstract}

Keywords: technical and vocational education, Textile, Clothing and Design, diverse academic backgrounds.

\section{Introduction}

Globally universities admit students from diverse backgrounds that include different financial backgrounds, traditional settings, various disabilities, private and public schools and those with different academic backgrounds. The universities have an obligation to accommodate all the students in various educational programmes and ensure that they acquire relevant skills and knowledge (ATF, ILO \& UNESCO, 2012; Charema, 2010; Kimura, 2013). The TVE in Zimbabwe was rationalised in 1990 when it was structured into five (5) levels which are Pre-Vocational Certificate (PVC), National Foundation Certificate (NFC), National Certificate (NC), National Diploma (ND) and Higher National Diploma (HND), (UNESCO and ZIMDEF 2005). The HND was equivalent to a general degree which was a technologist grade and was at the sixth level in the Zimbabwe Qualifications Framework (ZQF), (Nziramasanga, 1999). With effect from 2004 the polytechnics were able to upgrade technical and vocational education training qualifications to graduate and postgraduate levels by addition of only one year to the HND leading to Bachelor of Technology ( Honours) Degree. Currently the institutions of higher learning allow students to move from technical and vocational institution to the other without losing credits. However, the students get disadvantaged when they join universities because there is no national policy that guides such movements, (UNICEF \& UNESCO, 2005). The individual departments within universities are given discretion to place students from the TVE institutions at any level they deem necessary. The students doing Textile, Clothing and Design programmes are mostly affected in terms of content coverage at the universities considering their various background qualifications from the various private and government owned institutions.

From the course analysis in Textile, Clothing and Design Training institutions in Eastern and Southern Africa by Nguku (2013) the TCD programmes lack strong multi- disciplinary skills and application components, in which critical textile processes are not adequately addressed and there is minimal design management content. The issue of lacking quality in tertiary education has also been raised by Mawoyo (2013) who points out that after Zimbabwe's independence, the tertiary education system focused on 
increasing access to education without paying attention to issues of quality. The provision of Textile, Clothing and Design (TCD) programmes with regards to students with diverse academic backgrounds in universities of technology in Zimbabwe has led to various concerns raised by the textile and clothing stakeholders. The concerns include poor performance of students, high student failure rate, students drop outs, and late completion of programmes by students. This study therefore sought to examine how the TCD lecturers adapted the TCD programmes content to cater for the students with diverse academic backgrounds to engage teaching and learning that is meaningful, relevant and accessible to all the students.

Curriculum content adaptation involves selecting or negotiating topics and activities relevant to students' lives, backgrounds and future or imagined identities (Hockings, 2010). Respecting and valuing individual differences means autonomy is given to all students so that they can make choices to pursue their interests and develop their potential (Anderson \& Boyle, 2015; Bhebhe, Dziva \& Maposa, 2014). Lecturers should be capable of making a difference in each student's learning through quality content instruction that highly enables them to cater for student diversity (UNESCO \& UNEVOC, 2013; Dalton, Mackenzie \& Kahonde, 2012).

Universities programmes are designed in-house by the lecturers and they are approved by the national board (ZIMCHE) that governs the running of all universities within the country. A study by Nguku (2012) within Southern Eastern African (S.E.A) countries reveals that the curriculum development and review processes incorporated input from relevant partners and stakeholders and the programmes were benchmarked with some global institutions although the issue of catering for diverse students was not addressed. A study by Kamu (2007) established that the designed CAD courses were not adequately addressing specific areas of apparel design as the courses comprised basic introductory concepts such as Corel Draw, Adobe Photoshop and Adobe Illustrator reflecting.

A study carried out on student diversity and the Australian Curriculum found out that teachers adjust curriculum content and teaching and learning strategies according to students' age and individual students' needs (Australian Curriculum Assessment and Reporting Authority, (ACARA) (Anderson \& Boyle, 2015). The content adjustment is done by drawing content from the curriculum and emphasizing specific aspects of one or more of the general capabilities such as teaching targeted literacy or social skills with greater focus on general capabilities. The approach may result in loss of curriculum integrity due to generalization of the content aspects which may lead to loss of focus in relation to programme's learning outcomes. Felder \& Brent (2005) propose content integration technique in which curriculum instructors combine a number of subjects/ courses into one course. The students acquire basic knowledge in the subjects/ courses in the combination within a limited time provided for the course, thereby depriving students from acquiring indepth knowledge in the subjects/courses. The Pakistan Higher Education Commission emphasizes the need for preparing Fashion and Design curriculum considering a lot of knowledge, techniques and methodologies evolving globally, indicating that professionals must keep updated (Ali, 2011).

Other global studies reveal that most universities adapt their programmes' content into a wide range of lecturer coordinated programmes aimed at catering for students with diverse academic backgrounds (Vickers, McCathy, \& Zammit, 2017; Stephenson \& Rajendram, 2017; Williams \& Johnson, 2011; Mather \& Muchatuta, 2011). Such programmes include student pre-assessment, academic development units, foundation and extended learning programmes, targeted support programmes, peer mentoring and tutorial support, and in-service training and employment service. The programmes benefit the students although they require well trained manpower and adequate teaching and learning materials for effective delivering of the content.

The studies reveal content gaps in the programmes, reflecting the need for curriculum designers to cover up the missing links to fulfil stakeholders' requirements. However, catering for diverse students through curriculum content adaptation impacts on programmes' design and selection of implementation procedures by the lecturers. Lecturers' instruction and content adaptation techniques that attend to students' learning styles and needs remove barriers to learning and support individual students to achieve more academically (Shay \& Kilpert, 2013; Rosell \& Ondrik, 2013; Block, 2011). In light of this, the study sought to examine 
how the lecturers adapted the TCD curriculum to cater for students with various levels of background qualifications.

\section{Theoretical framework}

Differentiated instruction and cultural capital theoretical frameworks guided the researcher to understand content adaptation approaches used to cater for students with diverse academic backgrounds in the provision of TCD programmes at university level. Bourdieu's (1986) theory of cultural capital base educational attainment on class inequalities and class reproduction in advanced capitalist societies. In this study, the class inequalities are equated to students who have various levels of academic backgrounds, denoted by their qualifications. Cultural reproduction relates to the link between original class membership and the ultimate class membership and how the link is mediated by the education system (Sullivan, 2002). The university lecturers should adapt curriculum content to link with the students' academic background knowledge to ensure effective teaching and learning among all the students.

The study was also guided by differentiated instruction model by Tomlinson (2005), who propounds that students learn best when their teachers accommodate the differences in their readiness levels, interests and academic profiles in curriculum implementation, with the main objective of taking full advantage of every student's ability to learn. The model requires teachers to be flexible in their approach to teaching and adapt the curriculum and presentation of information to students rather than expect students to modify themselves for the curriculum (Hall, Strangman \& Meyer, 2003; Tomlinson, 2003; Wilson, 2012). The framework informs lecturers on curriculum planning and instruction to ensure all the various qualifications of students are catered for.

\section{Statement of the problem}

The Ministry of Higher and Tertiary Education in Zimbabwe, through universities of technology, is continuously expanding the provision of TCD programmes despite the challenges that are being faced by the implementers and the students. Muzenda \& Duku (2014), OECD (2009) and most TCD stakeholders raise concern that the programme implementers have failed to cater for variance in students' academic qualifications which has impacted on the performance of students resulting in high students drop outs, student failure in some courses, and poor performance in other courses in the TCD programmes in universities of technology. The Financial Gazette (2003); The Sunday Mail (2013) \& Coltart, (2012) note that the performance of most students with qualifications such as NC, "O" level and "A" level (TCD) do not meet the expectations of industrialists. The textile and clothing stakeholders also raise concern, through ATF, ILO \& UNESCO (2012) and UNESCO \& ZIMDEF (2005), that, despite the training received by university lecturers, it is not clear whether the TCD lecturers are using the delivery strategies that cater for students' diversity in the implementation of TCD programmes.

\section{Research questions}

1. How do lecturers adapt the TCD curriculum content to ensure that students with diverse academic backgrounds are accommodated in the programmes?

2. What challenges are faced in adapting TCD curriculum content to cater for students with diverse academic backgrounds?

\section{Research objectives}

The study sought to:

1 examine strategies used to adapt the TCD curriculum content to ensure that students with diverse academic backgrounds are catered for.

2 establish challenges encountered in adapting TCD curriculum content to cater for students with diverse academic backgrounds. 


\section{Delimitations}

The study was conducted in 2 universities of technology in Zimbabwe that offer TCD degree programmes. Participants comprised quality assurance directors, TCD deans, department chairpersons, lecturers, and students from the two universities of technology.

\section{Methodology \\ Research paradigm}

The study adopted a post-positivist paradigm that relies on multiple methods of quantitative and qualitative orientation as a way of capturing as much of the reality of the study phenomenon as possible (Mackenzie \& Knipe, 2006; Toledo-Pereyra \& Luis, 2013). The use of post-positivist paradigm enabled the researcher to use various methods of data collection instruments that yielded both quantitative and qualitative data (Cresswell, 2014; Hofstee, 2011). Such combination of approaches neutralizes most of the weaknesses and biases of the methods and results in obtaining in-depth and comprehensive data that gives confidence to the researcher's findings.

\section{Research Approach}

The study adopted a mixed method approach which involved use of quantitative and qualitative data collection and analysis techniques in the same study. The mixed method approach enabled the researcher to effectively synthesize ideas from respondents on curriculum adaptation strategies used to cater for students from diverse academic backgrounds in the provision of TCD programmes at universities of technology in Zimbabwe (Johnson \& Christensen, 2011).

\section{Research Design}

The concurrent triangulation design was implemented as it uses both qualitative and quantitative data collection at the same time in order to provide a comprehensive analysis of the study problem (Creswell, 2014). The concurrent approach also provides a basis for triangulation of data as results from one method (quantitative or qualitative) can help to inform the other method.

\section{Population}

The population for this study comprised 2 universities of technology that offer TCD programmes in Zimbabwe, 2 quality assurance directors, 2 textile and clothing deans, 2 textile and clothing heads of departments, 70 lecturers, and 240 students.

\section{Sample and Sampling}

Purposive sampling technique was used to select participants for this study. Purposive sampling entails handpicking subjects to be included in the study basing on researchers' judgment of their characteristics (Creswell \& Clark, 2007; Teddie \& Tashkkori, 2009). Two universities of technology were chosen for the study, 2 Quality Assurance Directors, 2 TCD Faculty Deans of studies, 2 department chairpersons, 36 lecturers, and 24 students comprised the study sample.

\section{Data Collection, Instruments and Procedures}

The researcher made use of questionnaire, face-to-face semi structured interviews, focus group discussions and document analysis to gather data for the study. Face to face semi-structured interviews were conducted with 2 Quality Assurance Directors, 2 TCD deans, 2 chairpersons and 6 lecturers from the two universities of technology. Focus group discussions were conducted with 24 students. The students were divided into 3 groups of 8 each, comprising 2 groups from one university and one group from the other university. Questionnaire comprised open ended and closed questions was used to solicit data from 36 TCD lecturers. Use of document analysis in this study was aimed at so citing programmes and course outlines' descriptions, identification of trends, frequencies and interrelationships between course content and content adaptation procedures.

\section{Validity, reliability and member checking}

In qualitative data, validity was addressed through honest, depth, richness and scope of the data collected, the participants employed, the extent of triangulation and the objectivity of the researcher. In quantitative data, validity was addressed through careful sampling, appropriate instrumentation and appropriate statistical analysis of the data. To ensure reliability for this study, the instruments were edited by the 
supervisor and a group of critical friends that included $\mathrm{PhD}$ students and graduates with regard to readability, clarity, format, ease and adequacy of items. For member checking, the researchers returned to some study respondents for them to comment on whether the interpreted data were in congruent with their experiences.

\section{Ethical considerations}

Researchers are guided by ethics in their practice. In order to carry out the study, the researchers sought clearance from University of Fort Hare Research Ethics Committee, Zimbabwe Ministry of Higher and Tertiary Education, Science and Technology Development, and secured an introductory letter from the University of Fort Hare to confirm the intention to conduct a study with two universities of technology in Zimbabwe. The researchers also observed participants' interest and well-being by ensuring voluntary participation in the study.

\section{Data Analysis}

The collected data were analysed quantitatively and qualitatively respectively. The issues arising from the questionnaire, interview, focus group discussions and curriculum documents were analysed concurrently to address the main research question (Cresswell, 2013).

\section{Results and discussion}

In response to the question on how lecturers adapted TCD curriculum content to cater for students with diverse academic backgrounds, twenty (55.6\%) lecturers indicated that they adjusted the quantity of content aspects in order to cater for students with diverse academic backgrounds. Another 55.6\% (20) of the lecturers said that they catered for the students by adapting the ways instruction was delivered to students. Eighteen $(50 \%)$ lecturer respondents noted that they adjusted the level of individual assistance in catering for students with diverse academic backgrounds. However, considering the large number of students per class in TCD provision, individual attention would require more time and adequate resources. Seventeen (47.2\%) lecturers said that they adapted the curriculum content by drawing content from the programme and emphasizing specific aspects to cater for the students. In this view, the specific aspects of the content that is selected requires thorough attention as the students have unique knowledge gaps because of their diverse academic backgrounds. Seventeen (47.2\%) lecturers noted that they adapted the time that is allocated to tasks during lessons to accommodate the students. The other $17(47.7 \%)$ lecturers indicated that they adapted the skill level, problem type and rules on how students approached the content. Ten (27.8\%) respondents said that they adjusted the student output to meet the needs of the students. Twenty-five percent (9) of the lecturer respondents indicated that they adjusted student participation. Six (16.7\%) lecturers said they adjusted the programme content by equivalent qualification level. The other $16.7 \%$ (6) noted that they alternated outcome expectations of the programme to accommodate students with diverse academic backgrounds. Three $(8.3 \%)$ lecturers indicated that they substituted curriculum content in order to cater for students with diverse academic backgrounds. One respondent noted that he/she allocated more time to teaching the fundamentals and preliminary knowledge for the programme. The other one mentioned that teaching students with common challenges separately was the technique that he/she employed to cater for the students with diverse academic backgrounds.

Most respondents indicated that they adjusted the quantity of content aspects and adapted ways in which instruction was delivered to students. Adjusting quantity of content may benefit some students and disadvantage other students at the same time. When a lecturer adjusts content by removing some concepts, the students who may not have learnt the concepts before, may not benefit since they lack exposure to background content knowledge in the concepts. If the lecturer enriches the content, those with strong background knowledge benefit since they easily cope with the enrichment. Those students who have not covered the basic concepts before may not effectively cope with the enrichment as they do not have basic knowledge about the planned content. However, a combination of different adaptive techniques may benefit students with diverse academic backgrounds.

The interview respondents gave their views on how the lecturers adapted the TCD content to cater for students with diverse academic backgrounds, and these are presented next. 
The quality assurance directors commented that the lecturers adapted the programme content by breaking it down into courses and course outlines that reflect breakdown of content from simple to complex, and by having the core courses such as Chemistry and Physics with introductory content first. Their responses are captured in the statements below.

QAD1 said that:

When the content that has been consulted first is packaged into course outline, the course outline spells the content level, the gradual development of the content level which originates from lower level to higher level covering all the levels. The skills they do should match the content levels.

The faculty deans of studies argued that the programmes' content should not be adapted. They advocated the adaptation of teaching and learning methodologies to suit the diverse students' needs. FD2 echoed the same sentiments as QAD2 who commented that they have broken programmes in such a way that they have simple courses with general content taken by all the students in first year.

FD1 pointed out that:

That will be the issue of methodology because the content the programme is supposed to provide for should be there whether a student is deficient in what or that. This is what our competencies are in terms of our graduate. It's a student who knows 1, 2, and 3 from the set content. But what should vary from class to class is the methodology used by lecturers. The students can be assisted through tutorials by academics. These tutorials need to be turned a little bit to the lighter side of 12 students per class since there are very large classes of 30 to 50 students.

DC1 agreed with QAD1 and FD2, but DC2 further revealed that they adapted the programmes content at regular intervals to meet global technological advancements.

DC2 outlined that:

Adapting content with us is an ongoing process because we want to meet new developments in technology. Every 3 years, we do curriculum review.

The lecturers commented that they taught from the simple content to complex and employed mixed ability grouping in order to capture attention of all the students and also assist those in need during extra hours.

TCDL1 argued that:

I don't do anything to the programme. The programme encompasses everyone, but when it comes to, like when you are talking of catering for those other students, it's up to me now to give them extra tuition and sometimes I settle for tutorials, taught up lessons and also, I give them time to consult either me as the lecturer, other students or even other lecturers in the department. They can also get something like clarification of some issues not clear to them.

TCDL2 explained that:

When I offer my lectures, I try to like open up more for those who have unique backgrounds and also another way would be telling students, especially those lacking crucial core knowledge, give them areas to read on as a way of catering. Then the other way is peer group presentations. When you constitute the groups, you try to spread them to make sure each group has students who are well experienced and those who have little knowledge in the area for cross pollination of ideas, especially with those who have little knowledge in the area.

TCDL3, TCDL4, and TCDL5 agreed with the above lecturers that they start to teach basic concepts from the known to unknown. 
TCDL6 elaborated that:

Yes, we adapt the content like I have explained earlier on. The intention is not on removing other content which they have to cover. It's additional of some of the content. We add some of the things that would have been taken for granted.

Most of the interview respondents' responses confirm most of the lecturer respondents' view that the lecturers adjusted teaching methodologies in order to cater for students with diverse academic backgrounds. However, most of the questionnaire lecturer respondents indicated that they also adjusted the quantity of curriculum content to cater for the diverse students; a view that was not shared by the faculty deans of studies who argued that the content was not supposed to be adjusted because the programme content had set competencies for the graduates that should not be adjusted. Adaptation of curriculum content by curriculum implementers enables them to reach the capability of every student in classes comprising students from diverse backgrounds, for effective teaching and learning. The study findings indicated that there was a contradiction between the faculty management team (quality assurance directors, faculty deans and chairpersons) and the curriculum implementers (lecturers). Since the lecturers indicated that they lacked knowledge on how to deal with students' diversities, the adjustment of content by selecting specific content and skills could be attributed to that training deficiency among the lecturers, which may have a negative impact on TCD graduates as the students may end up lacking relevant knowledge and skills required in the textile and clothing industry. The TCD managers' opinion, is in agreement with Rosell \& Ondrik (2013) and Mather \& Muchatuta (2011) who say that when lecturers make adaptations, the programme should maintain the same learning outcomes although the learning goals, expectations, presentations, materials, assistance and environment may vary.

Other global studies reveal that most global universities adapt their programmes' content into a wide range of lecturer coordinated programmes such as student pre-assessment and academic development units aimed at catering for students with diverse academic backgrounds (Vickers, et al., 2017; Stephenson \& Rajendram, 2017; Williams \& Johnson, 2011; Mather \& Muchatuta, 2011). However, the current study's findings show that only one support programme (offering tutorials) was implemented by the two universities of technology, which could not adequately cater for students' diverse needs. The respondents commented that the tutorials were not effective as they were carried out with large classes in which most students' needs were hardly met.

The lecturer interview respondents' view that it was up to them to help those students who needed assistance as they had other things to attend to, reflects that the TCD management team was not much concerned with the teaching and learning of the students who joined the TCD programmes from diverse academic backgrounds. The management's lack of concern is also shown by the way the timetable was designed as the curriculum implementers were not afforded time to assist the students. Since the curriculum adaptation approaches employed by the lecturers were different from lecturer to lecturer as indicated by the study results, it shows that the TCD management were reluctant to foster and monitor effective curriculum adaptation procedures for the benefit of all the TCD students from diverse backgrounds. However, Saraceno, (2014) and Hansen \& Mastekaasa (2006) argue that students' capital (various academic backgrounds) may be utilized by the universities by enabling them to resource the departments with relevant current technological equipment and manpower that may assist the lecturers to design and adapt TCD subjects' content to enhance teaching and learning of the students.

The curriculum recipients (students) were asked to put across their views on whether the content was adapted to meet their diverse needs or not.

SFG2 said that:

The programme has background knowledge, no matter where you are coming from or what you have done. It begins with Introduction to Design and the like. However, there is need for the lecturers to keep updated on the internet and maybe do exchange programmes so that they are up to date with technology, be it new information, theoretically or practically. There 
is need for lecturers to do extension programmes as well for them to present up to date, relevant information.

Most of the students shared the same sentiments with the interview and questionnaire respondents, that the programmes' content is structured from simple to complex, from introductory courses to those that are challenging. However, what is simple to some students may not be simple to other students as their background qualifications are different. The study results shows that there was need for further adaptation of curriculum content to meet the needs of the students. The students further argued that the lecturers lacked knowledge in advanced technology and skills in the TCD field and in curriculum delivery (which encompass curriculum adaptation). Integration of technology in planning teaching and learning is relevant as most teaching and learning Information Communication Technology (ICT) packages facilitate varying of content adaptation procedures. Variation of adaptation procedures enables lecturers to cater for different learning styles and learning needs among students from diverse backgrounds. Tomlinson (2005) differentiated instruction model requires lecturers to be flexible in their approach to teaching and adapt the curriculum and presentation of information to students instead of students having to modify themselves for the curriculum.

\section{Challenges encountered in adapting curriculum to cater for the students.}

Most of the lecturers $(35,97 \%)$ faced challenges of shortage of resources to cater for the students, 34 (94.4\%) lecturers said they were facing problems in designing accommodative strategies and in adapting subject content to meet the needs of the students, because they lacked knowledge on strategies for catering for diverse students and that they did not have adequate TCD subject content knowledge. Thirty (83.3\%) lecturers indicated that they had problems of high student to lecturer ratio which prevented them from attending to all the needs of the students during the lessons. Twenty-five (69.4\%) lecturer respondents reflected that they were experiencing problems of working extra time outside the timetable in order to assist the students to cope with university content as well as background content in the TCD field. The other 25 (69.4\%) lecturers said they had problems in motivating the students who lacked background exposure to TCD subjects' knowledge and skills since most of those students quickly lost hope and focus. Twenty four (66.7\%) lecturer respondents noted that they had challenges of inadequate manpower in the form of lecturing staff, teaching assistants and technicians. Twenty (55.6\%) lecturers indicated that they were worried by the wide performance gaps among the students, drop outs, and absenteeism. The respondents' views reveal that they were mostly affected by inadequacy of resources and lack of knowledge on how to deal with student diversity at the two sampled universities that offer TCD programmes. These challenges are critical because resources and continuous staff development enhance students' interaction with subject content and skills as they pave way for optimum teaching and learning among the students.

The interviewed respondents revealed that

QAD1 said that:

Basically we do not have resources. We critically need resources, such as ICT learning packages to virtualize teaching and learning processes, and to cater for the diverse students. Pacing of lessons and timing of the end period of projects is very difficult in poorly resourced learning environments. Some students do not get to optimum achievement due to the time issue. Lecturers work overtime going up to 20 hours instead of 8 hours a day.

TCDL3 said that:

The other critical challenge is on aligning curriculum content to suit the different backgrounds of students. We do not have enough resources such as physical infrastructure and teaching assistants to cater for the students with different academic levels. The lecturing staff has limited knowledge on how to cater for the students with diverse academic backgrounds. There is lack of support from the university management and administrators for the TCD departments.

The study found out that there were various challenges experienced in adapting the TCD curriculum to cater for students with diverse academic backgrounds. The challenges included lack of knowledge to adapt the 
curriculum in order to cater for student diversities and little subject content knowledge among lecturers, inadequate university support, high lecturer-student ratio, inadequate teaching and learning materials, shortage of manpower, and inadequate time to attend to student diversities in order to achieve learning outcomes. The study finding of inadequate resources within the sampled institutions is in line with Masuku \& Muchemwa (2015) observation that universities in Zimbabwe were poorly resourced in teaching and learning resources such as infrastructure, materials and human resources. The findings of the studies in other African countries also point to the same issue of inadequacy of resources across most university institutions (Nguku, 2012, 2013; Olasumbo \& Toyin, 2009). Fry et al. (2009) argue that the student increase in numbers, internationalization of tertiary education and a wide increase in students' educational experiences have placed pressure on institutional resources. The study findings revealed that the challenges may be solved through regular staff development focussing on catering for student diversities in university programmes' provision and availing of relevant support services by the institutions.

\section{Conclusions}

The findings of the study revealed that the lecturers adapted the TCD curriculum content using various methods due to their commitment to their work as there was no policy to govern curriculum adaptation strategies used to cater for students with diverse academic backgrounds in the provision of TCD programmes at university level. The study established that the lecturers faced challenges in adapting the programmes' content to cater for students with diverse academic backgrounds. The challenges experienced were inadequate time to attend to individual students, difficulty in planning and managing lesson activities, inadequate teaching and learning equipment and materials, not enough infrastructure, high student-lecturer ratio and inadequacy of lecturers and support staff like technicians, tutors and teaching assistants.

\section{Recommendations}

Basing on the findings of the study, the researchers recommend that:

- Universities in Zimbabwe, in collaboration with higher education policy makers, should come up with programmes provision policies that guide the higher education institutions in catering for students who enter universities with diverse academic backgrounds. This will enable the institutions to provide appropriate support and guide lecturers to come up with relevant curriculum adaptation strategies that fully address the needs of the students from diverse academic backgrounds.

- University institutions should support and organize staff development programmes focusing on updating lecturers' subject content knowledge and skills, and pedagogical content knowledge and skills to cater for students from diverse backgrounds.

- The TCD departments should initiate collaborative activities with industry, curriculum development boards and other institutions that offer similar programmes and those that prepare students for university education. This enables the development of programmes that link each other in content progression up to university education level.

- There should be interactive participation of all members of each TCD department, students and university management team to design effective programmes adaptation procedures to cater for students who enter university education from diverse backgrounds.

\section{Acknowledgements}

My foremost appreciation goes to God Almighty; the only source of my inspiration, wisdom and strength for making this study a success. Lord, I am indebted to you. Thank you Lord!

My sincere thanks go to the university management of the two universities of Technology in Zimbabwe that authorized the study, and to the entire quality assurance directorate, faculty deans, chairpersons and lecturers who shared information with me to make this study possible.

\section{References}

[1] Ali, Z. (2011). Higher Education Commission Islamabad-Pakistan. Meeting held at HEC Regional Center, Lahore from 21-23 April. 
[2] Anderson, J., \& Boyle, C. (2015). Inclusive education in Australia: rhetoric, reality and The road ahead. Support for Learning, 30(1), 4-22.

[3] ATF, ILO \& UNESCO. (2012). Proposed Indicators for Assessing Technical and Vocational Education and Training. Inter-Agency Working Group on TVET Indicators. UNESCO.

[4] Bhebhe, S., Dziva, M. \& Maphosa, C. (2014). Towards a differentiated an Vocational Oriented Secondary school curriculum in Zimbabwe Mediterranean Journal of Social Sciences, 5(7), 443-450.

[5] Block, M. E. (2011). Simple curriculum and instructional modifications for inclusive Physical education. Online website: http//www.inclusive_physical_eduction Html.

[6] Bourdieu, P. (1986). The Forms of Capital. In Handbook of Theory and Research For the Sociology of Education. Edited by: Richardson J. New York: Greenword.

[7] Charema, J. (2010). Inclusion of primary school children with hearing impairments in

[8] Coltart, D. (2012). Education for employment, developing skills for vocation. Speech At the African Innovation Summit, 5-7.Retrieved from African Brains Website: http://www.youtube.com/watch? Retrieved 16-04-2015. Zimbabwe. Africa Education Review, 7(1), 85-106.Online website http://www.tandfonline.com/loi/raer20. Retrieved 23-10-2016.

[9] Cresswell, J. W. (2013). Qualitative Inquiry and research design: Choosing among The five approaches. Thousand Oaks, CA: Sage Publications. Inc.

[10] Cresswell, J. W. (2014). Research Design. International Student Edition. Qualitative, Quantitative and Mixed Methods Approaches. London: SAGE.

[11] Dalton, E. M., Mckenzie, J. A., Kahonde, C. (2012).The Implementation of Inclusive Education in South Africa: Reflections arising from a workshop for teachers And Therapist to Introduce Universal Design for Learning. African Journal Of Disability, 1(1), 12-20. Online website: http://dx.doi.org/10.4102/ajod.v1i1.13.Retrieved 21-02-2015.

[12] Felder, R. M. \& Brent, R (2005). Understanding Student Differences. Journal of Engineering Education, 94(1), 57-72.

[13] Financial Gazette, (2003, December, 8). Zimbabwe Chaos in the Classroom.

[14] Financial Gazette, p, 1, http://www.developmentgap./aweapon.htmlAccessed

[15] Fry, H., Ketteridge, S. \& Marshall, S. (2009). A handbook for teaching and learning in Higher Education. Enhancing academic practice. New York: Routledge.

[16] Hall, T., Strangman, N., \& Meyer, A. (2003). Differentiated instruction and Implications for UDL implementation. Wakefield, MA: National Centre on Accessing the General Curriculum. Online website: http://www.cast.org/publications/ncac/ncac_diffinstructudl.html.

[17] Hansen, M. N. \& Mastekaasa, A. (2006). Social origins and academic performance At university. Oxford university press, 22 (3), 227-229.

[18] Hockings, C. (2010). Inclusive learning and teaching in higher education: A

[19] Synthesis of research. Online website http://www.heacademy.ac.uk/evidencenet. Retrieved 29-082016.

[20] Hofstee, E. (2011). Constructing a good dissertation. Online website: http://www.constructing-agood-dissertation-erik-.

[21] Johnson, B. and Christensen, L. (2011). Educational Research: Quantitative, Qualitative and Mixed Approaches. ( $4^{\text {th }}$ ed.). New Delhi: Sage Publications.

[22] Kamu, V. W. (2007).Assessment of the adoption of apparel computer aided design Technology training in selected public universities in Kenya. H60/10169.

[23] Kenedy, U. E. (2013). Functional Vocational and Technical Education Curriculum forSustainable Youth Empowerment. UK: British Journal of Education,

[24] Kimura, M. (2013). Non-performativity of university and subjectification of students: The Question of equality and diversity in UK universities. British Journal of Sociology of Education, 35 (4), 523540.

[25] Mackenzie, N. \& Knipe, S. (2006). Research Dilemmas: paradigms, methods and Methodology. Issues in Educational Research. 16:193-205. Online website: www.iier.org.au/iier16/mackenzie.html.

[26] Mather, G. \& Muchatuta, M. (2011). How to teach with inclusive practice. Learning Through Diversity. Macquarire University. Faculty of Business and Economics. Online website: http: //www.mq.edu.au/Itc/resources.htm. 
[27] Masuku, S. \& Muchemwa, S. (2015). Occupational stress among university lecturers: A case of Zimbabwe. U. S. A. David publishers, 5(4), 258- 266.

[28] Mawoyo, I. (2013).Zimbabwe. A Profile of Higher Education in Southern Africa. 2(16): 34-47.

[29] Muzenda, V. \& Duku, N. (2014). Examining Relationship between the Clothing and Textiles Curriculum and the World of Work. Mediterranean Journal of Social Sciences, 5(16), 409-414.

[30] Nguku, E. (2012). Analysis of textile and clothing training institutions in the East-Southern Africa.

[31] Nguku, E. (2013). Course Analysis and Gaps Identification in Selected Textile and Clothing Training Institutions in East - Southern Africa. ACTIF, ICIPE.

[32] Nziramasanga, C. T. (1999). Zimbabwe Report of the Presidential Commission of Inquiry into Education and Training. (August 1999).

[33] OECD, (2009).Tertiary Education for the Knowledge Society. Thematic Review of Tertiary Education: Synthesis Report. Online website: ww.oecd.org/newsroom/40556222.pdf. Retrieved 2206-2015.

[34] Olasumbo, O. A. \& Toyin, A. F. (2009). Work family conflict, job satisfaction and Labour turnover intentions among state university lecturers. Nigeria: Higher Education.

[35] Rosell, S. \& Ondrik, K. (2013). The inclusive school. Online website: http//www. School_of_educators.com. Retrieved 22-04-2015.

[36] Saraceno, C. (2014). Do we need capital accounts for culture? In Joint IEA/ISI Strategic Forum 2014 and Workshop of the High-level Expert Group On the Measurement of Economic Performance and Social Progress on Intra-generational and Inter-generational Sustainability, Rome (pp. 22-23).

[37] Shay, S. \& Kilpert, L. (2013). Kindling fires: examining the potential for cumulative Learning in a journalism curriculum. Teaching in Higher Education. 18(1): 40-52. DOI:

10.1080/13562517.2012.678326. Online website

http://www.openuct.uct.ac.za/sites/default/files/UCTOpenAccessPolicy.pdf

[38] Stephenson, G. K., \& Rajendram, S. (2017). Expanding Access While Narrowing Outcomes. The Future of Accessibility in International Higher Education

[39] Sullivan, A. (2002).Bourdieu and education: How useful is Bourdieu's theory for Researchers? Netherlands: The Netherlands Journal of social Sciences, 38(2).

[40] Teddie, C. \& Tashkkori, A. (2009). Foundations of mixed methods Research Integrating Quantitative and Qualitative Approaches in the Social and Behavioral Sciences. SAGE Publications, Inc. U.S.A. Online website: http://us.sagepub.co/en-us/foundations-of-mixed-methodsResearch/book226302. Retrieved 13-09-2015.

[41] Toledo- Pereyra \& Luise, H. (2013). Principles of Research: From Idea to Publication. New York: Nova Science Publishers Inc.

[42] Tomlinson, C. A. (2003). Deciding to teach them all. Educational Leadership 61(2), 6-11

[43] Tomlinson, C. A. (2005). Grading and Differentiation: Paradox or good practice? Theory into Practice, 44 (3), 262-269.

[44] UNESCO \& ZIMDEF, (2005). Ministry of Higher and Tertiary Education. Report onTechnical and Vocational Education and Training. Policy Review Framework.

[45] Harare: UNESCO. Online website: www.unesco.zimdef.org. Retrieved 14-07- 2015.

[46] UNICEF \& UNESCO, (2005). National Action Plan of Zimbabwe. Education for All Towards 2015. Harare: UNESCO. Online website: http:/www.unevoc.ne Retrieved 18-06-2016.

[47] UNESCO - UNEVOC (2013). Revising global trends in TVET: Reflections on theory And practice. UNESCO. Online website: www.unevoc.unesco.org. Retrieved 13-04-2016.

[48] Vickers, M., McCathy, F. \& Zammit, K. (2017). Peer mentoring and intercultural Understanding: Support for refugee- background and immigrant student Beginning university study. International journal of intercultural relation Online website: https: //doi.org/10.1016/j.ijintrel.2017.04.015. Retrieved 13-10-2016.

[49] Williams, C. T. \& Johnson, L. R. (2011). Why cannot we be friends? Multicultural Attitudes and friendships with international students. Norway: International Journal of International Relations, 35 (1), 41-48. Online website: https://doi.org/10.1016/j.ijintrel.

[50] Wilson, W. J. (2012). The truly disadvantaged: The inner city, the underclass, and Public Policy. University of Chicago Press. 